\title{
Expectativas acadêmicas de alunos do curso de formação de sargentos combatentes do exército
}

\author{
Academic expectations of army combatants sergeants course \\ http://dx.doi.org/10.5007/2178-4582.2017v51n2p421
}

Osmar Prata Machado

Universidade Estadual do Rio de Janeiro, Rio de Janeiro/RJ, Brasil

Reivani Chisté Zanotelli Buscacio

Universidade Veiga de Almeida (UVA), Rio de Janeiro/RJ, Brasil

\author{
Marcia Cristina Monteiro, Fátima de Almeida Maia, Denise Amorim Rodrigues \\ e Adriana Benevides Soares \\ Universidade Salgado de Oliveira, Rio de Janeiro/RJ, Brasil
}

\begin{abstract}
Este estudo buscou investigar as expectativas de jovens alunos do curso de formação de sargentos combatentes do exército no que diz respeito à instituição, ao relacionamento interpessoal, ao status social e salário e à influência familiar. Participaram 292 alunos com idades variando entre 18 e 26 anos. Foi utilizado um questionário construído especialmente para este estudo baseado nas características da instituição militar de ensino e aplicado em um único momento de forma coletiva na instituição. $\mathrm{O}$ estudo concluiu que embora os jovens desejem seguir uma carreira militar devido à estabilidade e à segurança, por ela proporcionados, conhecem pouco sobre a rotina militar. Esses dados mostram a relevância de conhecer as expectativas dos alunos para melhor conduzir processos educativos e de inclusão as rotinas específicas de sua formação.
\end{abstract}

Palavras-chave: Aspirações educacionais. Ensino Superior. Formação militar.
This study aimed to the students of the course of training fighters Army sergeants, investigate the expectations of these young people with regard, the institution, the interpersonal relationship, social status and salary and family influence. 292 students participated with aged between 18 and 26 years. A questionnaire was specially constructed for this study based on the characteristics of the military education and applied in a single moment in collective form at the institution. The study found that although young people wishing to pursue a military career, mainly due to the stability and security provided by it, they know little about the military routine. Besides these factors, family influence and social status were also considered strong factors in career choice. These data show the importance of meeting the expectations of students to better conduct educational processes and include specific routines of their training.

Keywords: Educational aspirations. Higher education. Military training.

\section{Introdução}

O Exército Brasileiro (EB) constitui uma das Forças Armadas do Brasil que está presente em todo o território nacional com objetivos constitucionais claros, além de estabelecer a presença do Estado Brasileiro e sua soberania. Assistimos a um número significativo de jovens que entram no ensino superior 
militar buscando oportunidades para o aprofundamento e conhecimento de uma carreira nas Forças Armadas.

O ensino superior militar contemporâneo vem enfatizando a necessidade de uma formação voltada para um conhecimento capaz de traçar a postura profissional dos militares, bem como oportunizar experiências para o aprimoramento das capacidades do indivíduo, mudando de uma visão sedimentada para uma perspectiva de aperfeiçoamento mais próxima da realidade atual, que busca os conhecimentos, o saber fazer e as competências necessárias para a realização de suas atividades (LUCHETTI, 2006; SCHAFFEL, 2010).

A escola de Sargento das Armas (ESA) é o estabelecimento de ensino destinado à formação e aperfeiçoamento dos sargentos de carreira do EB e o curso apresenta equivalência à formação superior civil. $\mathrm{O}$ ingresso e o curso são regidos por legislação específica (ESA, 2016) como a Lei de Ingresso (12.705, de 8 de agosto de 2012), Estatuto dos militares (Lei $\mathrm{n}^{0} 6.880$, de 9 de dezembro de 1980) e dos Ex-Combatentes da 2a. Guerra Mundial (Lei no 5.315 , de 12 de setembro de 1967). Tem por objetivos fortalecer os valores, deveres e a ética militar. O quantitativo de vagas oferecidas no último concurso (2015) foi de 1.410, conforme o Manual do Candidato (Ministério da Defesa, 2015). As vagas são para combatente/logística-técnica/aviação (infantaria, cavalaria, artilharia, engenharia, comunicações, intendência, armamento, mecânico) saúde e música. O candidato ingressa por concurso público, passando por diferentes etapas de seleção: provas de conteúdos curriculares do ensino médio (português, redação, matemática, geografia e história), prova de conhecimento específico e de títulos, no caso de oferta de vagas para postos de saúde e música, inspeção de saúde e de aptidão física. O aspirante aprovado permanece em regime de internato e recebe proventos previstos em lei. $\mathrm{O}$ curso é dividido em duas etapas: período básico (34 semanas) e de qualificação (43 semanas). O curso básico é realizado em diferentes estados da Federação: Ceará, Goiás, Minas Gerais, Mato Grosso do Sul, Pará, Pernambuco, Rio Grande do Sul, Rio de Janeiro, São Paulo e Santa Catarina. Após o período básico e dependendo do desempenho, o aluno poderá ser designado para uma das unidades que apresente a opção de vaga para a qual se inscreveu, concluindo esta fase nas cidades de Três Corações/MG, Rio de Janeiro/RJ e Taubaté/SP. O estudante também participa de atividades sociais, culturais, recreativas e esportivas. A formação do militar, portanto, não se restringe a casos de guerra. Sua formação é voltada para a gestão de pessoas, de bens ou de materiais (PAIVA, 2012).

Formar um militar, seja ele sargento ou oficial, exige uma série de investimentos que objetivam o preparo do jovem que entra para a Escola 
Militar. O candidato chega a este estabelecimento de ensino por concurso, entre o final da adolescência e o início da vida adulta oriundo de diversas regiões do país. Pode existir alunos de todas as unidades da federação com culturas as mais diversas possíveis e valores sociais que diferem em vários aspectos. Um dos grandes desafios desse sistema de ensino é equiparar todos esses jovens no que diz respeito a valores sociais e desenvolver a ética profissional necessária para a carreira militar (SILVA, 2008). Segundo o mesmo autor, a formação do oficial do EB perpassa por um rito de passagem que marca a saída da vida civil para a entrada na educação militar. A capacidade de viver na escola militar em regime de internato, usando uniformes, nomes de guerra, números de identificação, fazendo parte de locais de refeição e alojamentos, acelera o processo de formação e incorpora mais rapidamente uma forma de ser própria do militar.

\section{Formando um militar do EB}

Fazer parte do EB e ser um profissional militar consiste em desempenhar atividades específicas nas Forças Armadas Exército, Marinha e Aeronáutica, com os objetivos referentes à defesa nacional (BRASIL, 1964). Esse período de formação exige a aquisição de conhecimentos científicos que objetivam modificar radicalmente o jovem que entra para a Escola Militar. Quanto mais eficiente for sua formação maior será o envolvimento do indivíduo com os assuntos da profissão e melhor será seu desempenho nas missões específicas relacionadas ao serviço militar (LUCHETTI, 2006; SCHAFFEL, 2010).

Nesta perspectiva, percebe-se que a mudança da vida civil para a militar faz parte de um processo constante de adaptação do indivíduo à organização, no encontro de novos caminhos que envolvam a aprendizagem, a inovação, a motivação, garantindo atingir resultados mais satisfatórios para si e para o contexto militar (PICARÓ, SARMENTO; SIIVA, 2016). Ainda segundo o autor, a relação indivíduo-organização assume um papel fundamental, cada vez mais importante para os estudantes na criação de sentimentos de pertencimento ao grupo, garantindo um trabalho de equipe que melhore a funcionalidade na realização das tarefas e obrigações, permitindo o alcance de objetivos individuais e coletivos. Em pesquisa realizada por Schaffel (2010), com oficiais da ativa sobre a sua formação, foi apontado que o militar enfrenta uma dupla exigência, que é desenvolver a aprendizagem de ser reconhecido pelos outros e cumprir da melhor forma seu desempenho no grupo.

\section{Formação militar: as expectativas dos ingressantes}

É importante perceber que entrar para a Escola Militar requer do estudante vencer desafios que estão associados a mudanças de vida e que, de alguma 
forma asseguram uma formação a nível superior que o habilita seguir na carreira militar. O estudo de Almeida et al. (2012), embora realizado com estudantes civis, pode servir de parâmetro para a avaliação das expectativas de alunos que entram para a Escola Militar Superior, uma vez que os anseios e apreensões podem ser semelhantes nesta transição de formação. Almeida et al. (2003) citam que os estudantes antecipam essa transição entre sistemas de ensino de maneira muito positiva, porém muitas vezes de forma idealizada. Os autores ressaltam que as expectativas geradas por conta da aprovação em concurso público compõem esse quadro quando os aprovados, jovens de dezoito a vinte e cinco anos, imaginam o que irão aprender e que tipo de mudança ocorrerá no ambiente de aprendizagem para alcançarem o objetivo final, a formação profissional.

Segundo Schaffel (2010), existe hoje um entrelaçamento do mundo militar com o mundo civil. O profissional militar tem buscado um aperfeiçoamento no Ensino Superior, com a intenção de aprimorar seus conhecimentos acadêmicos. Os estudantes no período inicial da universidade podem passar por momentos difíceis quando, segundo Igue et al. (2008) é exigida maior integração e adaptação que são peculiares a esse início da vida adulta. Os estudos de Gomes e Soares (2013) relatam que as expectativas de estudantes que ingressam no Ensino Superior estão relacionadas com um modelo acadêmico que desconhecem e que irão precisar de novos recursos para enfrentar este desafio. Os autores ressaltam que a permanência dos estudantes no contexto universitário leva a mudanças significativas que envolvem aspectos cognitivos, emocionais e comportamentais que estão presentes desde a entrada do estudante na Universidade até a conclusão do seu curso.

Segundo estudo de Almeida et al. (2012), as expectativas são desejos e aspirações construídas no intuito de serem concretizadas, especialmente quando ocorre uma mudança de ciclo de estudos, como na migração do Ensino Médio (EM) para o Superior (ES). Esta transição poderia ser minimizada com informações que situassem os estudantes sobre a melhor maneira de conduzir a vida acadêmica, na promoção de uma maior integração ao ambiente universitário, bem como aos mecanismos de apoio psicossocial aos alunos com maiores dificuldades de adaptação.

As expectativas da formação militar: a integração social

Outra expectativa frequente é como irão encontrar novos amigos. Segundo Schaffel (2010), a socialização na formação militar vai ao encontro dos sentimento de pertencimento na qual o indivíduo estabelece sua relação com o outro. O processo vai se construindo e assumindo práticas relacionais entre as necessidades, desejos e valores dos diferentes grupos. As relações 
afetivas de amizade entre os alunos são construídas de maneira espontânea, mas sujeitas as condicionantes do meio o qual o aluno está inserido. Almeida et al. (2003) ressaltam que os laços de amizade construídos a partir da associação nos momentos difíceis são poderosos instrumentos motivadores que auxiliam os alunos a superar as dificuldades e suportar as adversidades típicas dos desafios físicos e psicológicos que fazem parte da rotina envolvida na sua formação.

Uma pesquisa realizada por Kantanis (2000) no campus principal de uma universidade australiana explorou o papel da transição social no ajuste dos estudantes no $1^{\circ}$ ano e constatou que a experiência universitária de um número significativo de alunos não é satisfatória em termos de realização pessoal, nem bem-sucedida em relação ao desempenho acadêmico. Dentre os fatores apontados tem sido atribuída responsabilidade deste desajustamento aos próprios estudantes e às escolas preparatórias de Ensino Médio uma vez que os mesmos se mostram pouco compromissados e precariamente preparados. Os estudantes mostram-se reticentes em discutir suas preocupações com os pais, professores e outros atores acadêmicos. A grande maioria escolhe amigos para compartilhar suas inquietações. A justificativa para escolher os amigos como confidentes foi saber que passam pelas mesmas dificuldades e que neste momento, precisam de um suporte moral para compartilhar as preocupações e frustrações (KANTANIS, 2000). Para Almeida et al. (2003), no contexto de qualquer ambiente educacional diferente do Ensino Médio está presente um campo psicossocial com dificuldades que podem ser superadas, isto é, haverá um ajuste ao novo ambiente de acordo com características pessoais e sociais dos alunos e peculiaridades acadêmicas próprias de cada instituição.

As expectativas da formação militar: envolvimento acadêmico e competências

Outras expectativas se configuram sobre o ambiente educacional. Observase que, à medida que o jovem se depara com a realidade do contexto militar o futuro oficial se integra e interage com o ambiente universitário de uma forma mais ampla e no ambiente de estudos de forma específica. Segundo Bravo (2008) existe uma especificidade no modelo de profissionalização dos estudantes, levando-o a uma contínua qualificação, que se liga à própria progressão na carreira. A profissão militar envolve dimensões de natureza individual e grupal, como a dedicação de tempo à formação, os anos de convivência levando o estudante a desempenhar atividades diversificadas em diferentes setores de interesse da instituição militar. Portanto, das exigências feitas na formação militar é construído um perfil de competências que vai estruturar a real missão do Ensino Superior Militar universitário: a capacidade de comunicação e a expressão, o raciocínio lógico, a visão sistêmica e 
estratégica, a criatividade e iniciativa, o intelecto adaptativo, flexível e a capacidade de negociação, a tomada de decisão, a liderança, o trabalho em equipe, o respeito aos direitos humanos, pelos valores da democracia, da justiça social e da cidadania. Portanto, uma formação integral, que exige do estudante um conjunto de exigências muito abrangentes.

Neste sentido, conforme postulam Fernandes e Almeida (2005), ao adentrar em um curso universitário, os jovens buscam cumprir as normas estabelecidas pela instituição como forma de evitarem problemas e assim alcançarem suas metas acadêmicas. Pode-se estabelecer um paralelo entre tal realidade e aquela dos cursos militares, sendo a disciplina militar um diferencial neste quesito. Segundo Neto (1999), a questão disciplinar no contexto militar refere-se não apenas às organizações hierárquicas, leis, ordens, mas à disciplina moral que une os diferentes segmentos das Forças Armadas. Para Silva (2007) a questão do caráter coletivo militar está baseada em aspectos como coragem, camaradagem, virilidade, combatividade e lealdade. Além disso, por se tratar de um curso profissional pode proporcionar estabilidade na futura profissão. A maioria dos alunos se esforça para assumir posturas que vão de acordo com a realidade encontrada.

Todos esses aspectos implicam em uma adaptação que pode transformar expectativas em frustrações, interferindo diretamente sobre o rendimento escolar dos alunos (CUNHA; CARRILHO, 2005). No caso dos cursos militares isso implica problemas ainda maiores do que no contexto civil, pois a classificação obtida pelos alunos ao final dos cursos pode proporcionar algumas vantagens, tais como escolher os lugares (cidades e quartéis) onde poderá servir, mas também pode interferir na promoção e na escolha para missões ao exterior (ESA, 2001). A rotina de formação do futuro sargento é, assim, carregada de exigências de toda ordem e faz com que os alunos passem a se preocupar, intensamente, em incorporar a cultura militar a que estão submetidos.

As competências militares a serem desenvolvidas durante o curso é outra questão que envolve expectativas. As competências não são tão evidentes nos primeiros meses, mas com o passar do tempo alguns alunos conseguem perceber que já incorporaram algumas delas, o que segundo Paradiso e Sarriera (2009), é o início da adaptação ao ambiente de trabalho. Os mesmos autores enfatizam que essa adaptação ajuda a desenvolver habilidades relacionadas à comunicação e ao relacionamento interpessoal e as habilidades pessoais; competências tão significativas para o militar de carreira. Também ressaltam que a contínua integração ao ambiente acadêmico promove mudanças nos estudantes de ordem não apenas comportamentais, mas também cognitivas e afetivas. Segundo 
Paiva e Feliciano (2010), as instituições militares apresentam um aspecto facilitador na construção das relações interpessoais entre os alunos por promoverem um ambiente de camaradagem, de equipe, o que facilita a integração de novos discentes.

As expectativas da formação militar: a família, os aspectos socieocnômicos na escolha da carreira

Aprender, portanto, depende das instituições e agentes geradores que estimulem e incentivem o envolvimento dos alunos nos aspectos sociais e acadêmicos, objetivando o desenvolvimento integral do estudante. A partir daí é importante que ele possa participar e sentir-se parte integrante do processo que está inserido (POLYDORO; AZZI, 2011). As expectativas pela carreira militar também estão relacionadas às dos familiares que desejam um novo profissional militar entre seus membros.

Segundo Groisman et al. (1996); Molina e Dias (2012), o legado está presente em muitas relações estabelecidas entre filhos de pais militares. Velho (2003, p. 16) destaca que na sociedade contemporânea "a divisão social do trabalho e a distribuição de riquezas delineiam categorias sociais distinguíveis com continuidade histórica". Os filhos se sentem envolvidos nesta atmosfera de expectativas paternas e procuram demonstrar sua lealdade na condição de filho, dando prosseguimento à carreira profissional iniciada pelo pai. Neste sentido, os filhos de militares recebem a influência profissional dos pais sem realizar o trabalho de orientação profissional e vocacional. Almeida e Pinho (2008) lembram que a escolha profissional não é tarefa fácil e se pauta por um processo de tomada de consciência de si mesmo a partir de várias reflexões.

Outra questão referente às expectativas refere-se à escolha da carreira. Bartalotti e Menezes-Filho (2007); Oliveira et al. (2009) afirmam que a pessoa quando escolhe a carreira leva em consideração fatores como a empregabilidade, o capital investido e o retorno esperado. O status que a carreira possibilita é um fluxo de utilidade dentre as opções apresentadas. A renda e o retorno financeiro, proporcionados pela carreira estão presentes nesta decisão. Ainda segundo os autores, a carreira militar juntamente com a Medicina, apresenta níveis baixos de desemprego o que contribui para que tanto os jovens quanto suas famílias invistam nessa possibilidade profissional futura.

Existe também a influência da situação econômica do meio social em que o aluno está inserido que determina a escolha por uma carreira militar. Paradiso e Sarriera (2009) afirmam que as escolhas profissionais muitas vezes estão pautadas por fatores ligados à própria classe social, etnia ou oportunidades que 
os indivíduos têm dentro da estrutura social a que pertencem. Neste sentido, estudo realizado por Sparta e Gomes (2005) aponta para o fato de que alunos do Ensino Médio de escolas públicas e privadas buscam o acesso ao Ensino Superior. Tal fato pode ser compreendido pelo desejo de ascensão social das classes, tendo como estímulo a valorização das profissões de nível superior em comparação com a desvalorização de outras ocupações. O estudo apontou ainda para o interesse dos estudantes por cursos que lhes favoreçam o ingresso mais rápido ao mercado de trabalho, provavelmente relacionado à realidade socioeconômica e ao aumento da renda familiar.

Parte-se do pressuposto que existe uma dissonância entre as expectativas e a realidade dos estudantes de cursos de preparação para a carreira militar assim como os enfrentados por alunos de cursos regulares de Ensino Superior, resultando em frustrações e iniciativas de superação das mesmas. Apesar das semelhanças, existem aspectos que são peculiares e exclusivos do aluno de instituição militar tais como a disciplina rígida e hierarquizada e o benefício do recebimento dos proventos. Os alunos, em sua maioria, provenientes de famílias de baixa renda, ao receberem o soldo encontram durante o curso a possibilidade de garantir uma atividade profissional, de se inserirem no mercado de trabalho e de se manterem estáveis no emprego (ROSSI, 2001; TRIGO, 2013).

Tendo em vista aspectos específicos da vida do estudante militar e a carência de estudos sobre a sua formação militar, esta pesquisa buscou junto aos alunos do curso de formação de sargentos combatentes do exército, investigar as expectativas destes jovens no que diz respeito instituição, ao relacionamento interpessoal, ao status social e salário e à influência familiar.

\section{Método}

\section{Participantes}

Participaram da pesquisa 292 alunos do curso de formação de Sargentos da Escola de Sargento das Armas (ESA), advindos de 14 estados brasileiros, sendo a maior concentração de candidatos do Rio de Janeiro (25\%). Ceará, Maranhão, Minas Gerais, Pernambuco, Rio Grande do Sul e São Paulo, totalizaram $10 \%$ cada um. Os estados da Bahia, Mato Grosso do Sul, Pará e Paraíba apresentaram 3\% cada e Piauí, Rio Grande do Norte e Paraná totalizaram $1 \%$ cada um. Todos os participantes tinham terminado a fase básica (turma de 2015) da formação e começavam a fase de qualificação. A idade média foi de 22 anos e desvio padrão de 1,82. Em termos de 
escolaridade 214 estudantes declararam ter o ensino médio (73,28\%), 72 o nível superior incompleto $(24,65 \%)$ e 6 o nível superior completo $(2,05 \%)$. No que diz respeito ao estado civil, 217 participantes $(74,31 \%)$ eram solteiros, $66(22,60 \%)$ casados e $9(3,08 \%)$ divorciados. É importante ressaltar que $218(72,18 \%)$ participantes são militares de primeira geração, sem histórico familiar de parentes militares.

\section{Instrumento}

O instrumento utilizado foi um questionário construído pelos autores especialmente para este estudo baseado nas características da instituição militar de ensino. É formado de quatro questões fechadas com cinco opções específicas de resposta e admitindo uma única escolha. Optou-se pelo modelo de questão fechada, considerando o tempo disponível para a aplicação e conhecimento dos tópicos mencionados pelos respondentes (GÜNTHER, 2003). A primeira questão era relativa às expectativas sobre o conteúdo acadêmico. É importante ressaltar que as opções "Apenas exercícios militares" e "disciplinas voltadas para o combate" referem-se a atividades e conteúdos tais como treinamento com armas (tiro e manutenção), simulações de combate e estratégias/táticas utilizadas em combate. A segunda tratava de expectativas sobre a inclusão no grupo social, a terceira se referia ao reconhecimento esperado; se social, familiar, salarial ou institucional e a última versava sobre expectativas do estudante e de sua família.

\section{Procedimentos}

O instrumento foi aplicado de forma coletiva, no auditório da instituição, em um único momento, no intervalo da rotina estudantil e com a devida autorização do setor responsável pelos discentes. Todos participantes assinaram Termo de Consentimento Livre e Esclarecido. Os dados foram computados em escores totais e percentuais de respostas.

\section{Resultados}

Tabela 1. Frequência de respostas à pergunta: Que conteúdo você esperava estudar na escola militar?

\begin{tabular}{|c|c|c|c|c|c|}
\hline Disciplinas & $\begin{array}{l}\text { Apenas } \\
\text { exercícios } \\
\text { militares }\end{array}$ & $\begin{array}{l}\text { Disciplinas de } \\
\text { universidades } \\
\text { civis }\end{array}$ & $\begin{array}{l}\text { Disciplinas } \\
\text { voltadas } \\
\text { para o } \\
\text { combate }\end{array}$ & $\begin{array}{c}\text { Disciplinas } \\
\text { de natureza } \\
\text { adminis } \\
\text { trativa }\end{array}$ & $\begin{array}{c}\text { Disciplinas de } \\
\text { universidades } \\
\text { civis aplicadas } \\
\text { à carreira } \\
\text { militar }\end{array}$ \\
\hline
\end{tabular}




\begin{tabular}{lccccc}
\hline Respostas & 59 & 8 & 192 & 4 & 29 \\
Percentual & 20,20 & 2,73 & 65,75 & 1,36 & 9,93 \\
\hline
\end{tabular}

As respostas mais frequentes provavelmente decorrem da experiência que tiveram durante o período básico da formação militar, cuja duração é de 34 semanas. Assim, observa-se que os discentes esperavam que durante o período de formação militar na escola, estudariam disciplinas voltadas para o combate, resposta que se apresentou como a mais frequente da amostra $(65,75 \%)$. Seguindo o mesmo raciocínio, fruto do primeiro ano na tropa, que é eminentemente prático, 20,20\% dos alunos acreditavam que não estudariam disciplinas, mas realizariam apenas, exercícios militares. As respostas indicam claramente a falta de informações dos estudantes sobre a segunda fase do curso.

De acordo com Luchetti (2006) o ensino do EB visa, primordialmente, formar um militar criativo, capaz de se aperfeiçoar constantemente e com iniciativa. Neste sentido, o ensino implica em atividades de cunho teórico, prático e profissional, que visam o exercício de atividades relacionadas à prática futura desses militares. Porém, nem sempre estes objetivos são explicitados para o aluno ingressante. Ao contrário, parece que este adentra a escola militar com uma visão, por vezes distorcida, deste momento em sua formação acadêmica, privilegiando os aspectos práticos da atuação do militar em situações de combate. Contudo, como aponta Luchetti (2006) o ensino de um militar deve ultrapassar o período de guerra, quando a sua atuação é a de abranger uma educação que possibilite ao militar experienciar de forma adequada elementos de sua profissão. Sendo assim, seria necessário que o estudante tivesse mais informação institucional sobre a sua própria formação para que suas expectativas não fossem tão diferentes da realidade encontrada, o que permitiria uma melhor adaptação e adesão ao curso (CUNHA; CARRILHO, 2005).

Tabela 2. Frequência de respostas à pergunta: Como você esperava se incluir no grupo social militar?

$\begin{array}{cccccc}\text { Forma de } & \begin{array}{c}\text { Comissão } \\ \text { de boas } \\ \text { vindas }\end{array} & \begin{array}{c}\text { Valorização } \\ \text { pela aprovação } \\ \text { no concurso }\end{array} & \begin{array}{c}\text { Atividades } \\ \text { sociais }\end{array} & \begin{array}{c}\text { Participando } \\ \text { de "trotes" }\end{array} & \begin{array}{c}\text { Na } \\ \text { convivência } \\ \text { cotidiana }\end{array}\end{array}$


$\begin{array}{llllll}\text { Percentual } & 4,45 & 39,04 & 4,45 & 3,08 & 48,97\end{array}$

Adaptar-se a um novo grupo social pode facilitar ou dificultar os objetivos individuais, por isso, observa-se que grande parte dos alunos acreditava que se incluiria no grupo social militar através da convivência cotidiana, apresentando $48,97 \%$ das respostas o que indica, indiretamente, que não acreditavam que ocorreria um evento específico que os socializaria. Também sobressaiu com o percentual importante de $39,04 \%$ que os alunos esperavam ser valorizados em função de sua classificação no concurso de admissão.

Participar de um grupo social é um importante fator que pode determinar o grau de adaptação do indivíduo ao contexto no qual está inserido (BOLSONISILVA et al., 2010), além de influenciar no seu bem-estar físico e psicológico. Por outro lado, o ingresso na vida acadêmica pode ocasionar dificuldades na habilidade do estudante se adaptar ao contexto universitário. Desta forma, segundo os mesmos autores, o estabelecimento de relações sociais satisfatórias é um importante preditor da possibilidade do indivíduo se sentir mais ou menos confortável em um determinado ambiente, como o acadêmico.

Tabela 3. Frequência de respostas à pergunta: Que tipo de valorização você esperava ao adentrar a escola militar?

\begin{tabular}{cccccc}
\hline Valorização & Salarial & Familiar & Social & Institucional & Outras \\
Respostas & 103 & 26 & 83 & 65 & 15 \\
Percentual & 35,27 & 8,90 & 28,42 & 22,26 & 5,13 \\
\hline
\end{tabular}

É possível observar que as expectativas indicadas na Tabela 3 evidenciam uma supervalorização do salário (35,27\%) seguida do status social (28,42\%). No Brasil, as instituições militares têm um valor de grande aceitação popular e credibilidade perante a opinião pública, segundo pesquisa do Instituto Brasileiro de Opinião e Estatística (IBOPE), publicada no portal "R7" em 2011. As Forças Armadas ocupam o segundo lugar, com $72 \%$ de aprovação no Índice de Confiança Social que mede a credibilidade das instituições brasileiras. Além disso, a carreira militar, sempre foi sociohistoricamente valorizada e isso, talvez, possa acrescentar ao jovem um status oferecendolhe reconhecimento social, uma melhor colocação no grupo de amigos e em especial, na sociedade. Nesse sentido, ingressar em uma carreira militar foi e ainda continua sendo o sonho de muitas famílias que almejam uma vida 
economicamente estável e com reconhecimento social. Essa pode ser uma das explicações que justifica ser o salário o tipo de expectativa mais comum apresentada pelos jovens.

Segundo Trigo (2013) é notório, nos quartéis, que a procura por salários mais compensadores é cada vez maior por parte da população de baixa renda, porém alguns estudantes também se identificam com os valores típicos da rotina militar o que influencia a sua escolha para a consecução da carreira. Dessa maneira, à medida que o sujeito se aproxima dos valores da instituição militar e compartilha da filosofia nela vigente percebe-se integrado e partícipe da organização, o que o leva a sentir-se valorizado socialmente e satisfeito com o curso.

Tabela 4. Frequência de Respostas à pergunta: Que expectativas foram comuns a você e à sua família por ocasião da entrada na escola militar?

\begin{tabular}{|c|c|c|c|c|c|}
\hline $\begin{array}{c}\text { Expectativas } \\
\text { comuns à } \\
\text { família }\end{array}$ & $\begin{array}{c}\text { Melhoria } \\
\text { salarial }\end{array}$ & $\begin{array}{l}\text { Seguir sua } \\
\text { vocação }\end{array}$ & $\begin{array}{l}\text { Perseguir a } \\
\text { felicidade }\end{array}$ & $\begin{array}{c}\text { Emprego } \\
\text { público c/ } \\
\text { estabilidade }\end{array}$ & $\begin{array}{c}\text { Assegurar } \\
\text { um futuro } \\
\text { melhor }\end{array}$ \\
\hline Respostas & 19 & 49 & 20 & 109 & 95 \\
\hline Percentual & 6,50 & 16,78 & 6,84 & 37,32 & 32,53 \\
\hline
\end{tabular}

Os dados apresentados na Tabela 4 mostram que as expectativas comuns entre os jovens e a sua família dizem respeito, principalmente à possibilidade de um emprego público com estabilidade (37,32\%) seguido da expectativa de que a carreira militar possa lhe assegurar um futuro melhor (32,53\%). As expectativas relativas à vocação, à felicidade e à melhoria salarial também aparecem, porém em menor proporção respectivamente $(16,78 \%, 6,84 \%$ e $6,50 \%)$.

No que diz respeito às expectativas relacionadas à entrada na escola militar, a ideia de estabilidade e de segurança, proporcionados por um emprego público, é uma forte tendência à escolha profissional. $\mathrm{O}$ fato de não poder ser mandado embora a qualquer momento apresenta-se como primordial tanto na expectativa do jovem quanto da sua família, representando a possibilidade de uma vida mais confortável e estável.

Estudo realizado por Oliveira et al. (2003) que teve como objetivo investigar as expectativas em relação à escolha da carreira militar de um grupo de recrutas no Exército da cidade de Barreiras/BA, identificou como fatores mais importantes para profissão, o salário e o plano de carreira além 
da possibilidade de promoção, de ter um emprego garantido, salários em dia e benefícios. A carreira militar mostrou-se ainda como um mecanismo de ascensão social, ficando a vocação como um estímulo secundário na escolha profissional.

Embora não seja possível negar sua existência, os resultados apontam que a vocação pela carreira, não é a expectativa mais importante almejada pelos jovens, $(16,78 \%)$. Esse resultado, que leva em consideração a comunalidade de opinião entre pais e filhos, pode ser explicado, em parte, por uma possível influência que a família tende a ter em relação ao futuro do jovem. Nessa lógica, é mais importante "garantir" um futuro seguro e confortável a fazer o que gosta, deixando de lado a vocação. Molina e Dias (2012) reforçam essa ideia a partir de um estudo realizado com 20 cadetes, alunos da Academia Militar das Agulhas Negras, que teve como objetivo investigar a influência exercida pelo pai, oficial do exército, na escolha da profissão. Concluíram que além do forte influxo do pai, outros fatores também cooperaram na decisão dos jovens em prestar o concurso para a área militar tais como, a segurança econômica, as amizades no colégio militar, a vocação, o gosto pelas atividades, a admiração pela carreira militar e a estabilidade financeira. Pode-se concluir então que é natural que os pais preocupados com o futuro dos seus filhos, queiram orientá-los para uma escolha bem-sucedida que a permita projetar realizações materiais para o futuro e, nesse caso, certos da possibilidade de estabilidade e segurança que a profissão oferece.

\section{Considerações finais}

Fazer um curso de Ensino Superior é ainda o desejo de muitos jovens e a realização do sonho de muitas famílias. Essa realidade também é válida para os jovens que se interessam em seguir a carreira militar. Porém, ser um militar de carreira demanda características específicas com as quais muitos jovens não conseguem dar-se conta que precisam desenvolver. Reconhecidamente, a profissão militar é alicerçada pela hierarquia e disciplina, o que exige do aluno ingressante o desenvolvimento de diferentes competências não só para a adaptação ao novo contexto como também, para a sua manutenção no mesmo e para a realização satisfatória do curso. No entanto, desenvolver tais competências pode não se mostrar uma tarefa fácil, pois muitas vezes, o jovem pode se sentir perdido diante de tantas cobranças ou até desestimulado e decepcionado frente a uma carreira que ele sempre sonhou. $\mathrm{O}$ fato de não perceber quais competências precisa desenvolver para melhor se adequar ao novo contexto, pode acarretar em prejuízos no seu próprio rendimento em relação ao curso. Considerando que as pesquisas neste campo são escassas, o estudo procurou contribuir através da investigação das expectativas destes jovens no que diz respeito, à instituição, ao relacionamento interpessoal, ao 
status social e salário e à influência familiar.

Observa-se que, ao iniciarem o curso, os jovens apresentam expectativas sobre o que acreditam que irão encontrar em relação aos estudos e as atividades de treinamento da qual participam. Porém, tais expectativas nem sempre correspondem à realidade. A concepção que os jovens têm do dia a dia militar parece estar desconectada, ou, pelo menos, afastada da realidade, pois estes mostraram que desconhecem a rotina militar e as exigências atribuídas à instituição de ensino. Neste sentido, também surge como expectativa desses jovens a necessidade de desenvolverem competências no próprio contexto pelo processo de inserção na organização desta rotina, ou seja, o jovem se vê em meio a um conflito, entre o que ele esperava encontrar e o que ele realmente encontra. Assim, a concepção inicial do jovem é, por vezes, reconfigurada em prol de um melhor ajustamento das suas necessidades ao contexto. No entanto, tal reconfiguração não parece ser simples, pois atravessa princípios, valores, crenças e própria motivação inicial em ingressar na carreira militar.

Outra expectativa observada foi que os alunos aguardam por um tratamento diferenciado por parte de seus superiores como forma de reconhecimento pelo esforço de terem conseguido ingressar no concurso, submetendo-se a todo processo de seleção. Tal reconhecimento e tratamento diferenciado nem sempre acontece, podendo levar o jovem a desenvolver sentimentos de frustração. Esta questão encontra eco nas expectativas dos alunos e de seus familiares em terem um membro militar na família uma vez que, ainda hoje, ter um profissional militar na família significa ter certo status social. O reconhecimento social deste profissional observado na sociedade brasileira é reforçado pelo fato da estabilidade no emprego e pelos proventos recebidos desde o período como aluno do curso de sargento combatente do EB. Diante da realidade social e econômica, este fator torna-se extremamente relevante para muitos estudantes que provêm, principalmente, de famílias de baixo poder econômico, pois significa a garantia da empregabilidade e da estabilidade financeira em uma organização pública.

Constatou-se ainda que, apesar das dificuldades enfrentadas, o aprendizado da rotina militar em relação à dedicação e a superação serviram como estímulos e uma forma para atingir os objetivos de ingressar na carreira. Por outro lado, seria de relevância também ter-se investigado as expectativas que são criadas no aluno ingressante quanto aos aspectos da estrutura da instituição e o que esta oferece, como biblioteca, espaço de desporto e lazer. Outro ponto relevante que pode ser investigado em estudos futuros, levando em consideração que o nível de frustração desses estudantes pode ser elevado diante da realidade 
que encontram, diz respeito à saúde mental. Finalmente, compreende-se que a limitação do estudo ocorreu pelo fato de ter privilegiado alunos de uma única instituição militar. Nesse sentido, estudos posteriores poderão englobar também um número maior de instituições militares, bem como desenvolver um estudo comparativo entre estas e instituições educacionais civis. Outra limitação pode ser compreendida na questão da pesquisa não ter mensurado as expectativas dos alunos antes e após terem iniciado o curso, pois esse dado poderá trazer uma expressão mais próxima da realidade sobre quais expectativas mudaram e quais das expectativas se mantiveram, como também associar as expectativas com os projetos de carreira. Dessa forma, há uma maior possibilidade desses jovens começarem a ser preparados não só em relação ao conteúdo do processo seletivo que os esperam para ingresso da instituição, como mencionado anteriormente, mas também preparados em relação à realidade da rotina da profissão.

\section{Referências}

ALMEIDA, L. S; COSTA, A.; ALVES, F.; GONÇALVES, P.; ARAÚJO, A. Expectativas acadêmicas dos alunos do ensino superior: construção e validação de uma escala de avaliação. Psicologia, Educação e Cultura, v. XIV, n. 1, p. 70-85, 2012.

ALMEIDA, L. S.; GONÇALVES, A.; SALGUEIRA, A. P; SOARES, A. P.; MACHADO, C; FERNANDES, E.; MACHADO, J. C.; VASCONCELOS, R.. Expectativas de envolvimento académico à entrada na Universidade: Estudo com alunos da Universidade do Minho. Psicologia: Teoria, Investigação e Prática, v. 8, p. 3-15, 2003.

ALMEIDA, M. E.; PINHO, L. V. Adolescência, família e escolhas: implicações na orientação profissional. Psicologia Clínica, v. 20, n. 2, p. 73-184, 2008.

BARTALOTTI, O.; MENEZES-FILHO, N. A relação entre o desempenho da carreira no mercado de trabalho e a escolha profissional dos jovens. Economia Aplicada, v. 11, n. 4, p. 487-505, 2007.

BOLSONI-SILVA, A. T.; LOUREIRO, S. R.; ROSA, C. F.; OLIVEIRA, M. C. F. Caracterização das habilidades sociais de universitários. Contextos Clínicos, v. 3, n. 1, p. 62-75, 2010.

BRASIL. Prestação do serviço militar. Lei Federal 4375. Brasília, DF, 1964. Recuperado de http://www.planalto.gov.br/ccivil_03/leis/14375.htm

BRAVO, A. B. O ensino superior público universitário militar: A importância de uma visão estratégica. Proelium: Revista da Academia Militar, v. 9, p.109-133, 2008.

CUNHA, S. M.; CARRILHO, D. M. O processo de adaptação acadêmica ao ensino superior e o rendimento acadêmico: adaptação e rendimento acadêmico. Psicologia Escolar e Educacional, v. 9, n. 2, p. 215-224, 2008. 
MACHADO, O. P. et al. Expectativas acadêmicas de alunos do curso de formação de sargentos...

ESCOLA DE SARGENTOS DAS ARMAS [ESA]. Portaria 2. Três Corações, 2001. Recuperado de http://www.esa.ensino.eb.br

FERNANDES, E. ; ALMEIDA, L. S. Expectativas e vivências académicas: Impacto no rendimento dos alunos do $1^{\circ}$ ano. Psychologica, n. 40, p. 267-278, 2005.

GOMES, G.; SOARES, A. B. Inteligência, habilidades sociais e expectativas acadêmicas no desempenho de estudantes universitários. Psicologia: Reflexão e Crítica, v. 26, n. 4, p. 780$789,2013$.

GROISMAN, M.; LOBO, M.; CAVOUR, R. Histórias dramáticas: terapia breve para famílias e terapeutas. Rio de Janeiro: Rosa dos Ventos, 1996.

GÜNTHER, H. Como elaborar um questionário. Série: Planejamento de Pesquisa nas Ciências Sociais, n. 1, p. 1-15, 2003.

IGUE, É. A.; BARIANI, I. C.; MILANESI, P. V. Vivência acadêmica e expectativas de universitários ingressantes e concluintes. Psico USF, v. 13, n. 2, p. 155-164, 2008.

KANTANIS, T. The role of social transition in students' adjustment to the first-year of university. Journal of Institutional Research, v. 9, n. 1, p. 100-110, 2000.

LUCHETTI, M. S. R. O ensino no exército brasileiro: histórico, quadro atual e reforma. (Mestrado em Educação) - Curso de Pós-Graduação em Educação, Universidade Metodista de Piracicaba. Piracicaba, 2006. 172f .

MINISTÉRIO DA DEFESA. Exército Brasileiro. Escola de Sargentos das Armas Max Wolf Filho. Manual do candidato 2015. Recuperado de http://www.esa.institucional.ws/site/ Legislacao.aspx

MINISTÉRIO DA DEFESA. Exército Brasileiro. Escola de Sargentos das Armas Max Wolf Filho. Legislação. Recuperado de http://www.esa.institucional.ws/site/Legislacao.aspx.

MOLINA, S. F. L.; DIAS, C. M. S. Ser oficial combatente do Exército: uma delegação transgeracional? Estudos de Psicologia, v. 29, n. 1, p. 143-152, 2012.

NETO, A. F. A pedagogia no exército e na escola: a educação física (1920-1945). Motrivivência, v. 11, n. 13, p 35-62, 1999.

OLIVEIRA, D. V. S.; SENA, J.; RIBEIRO; M. N. G. A.; NUNES, W. F. Um estudo sobre as expectativas de um grupo de recrutas com relação ao trabalho desempenhado no exército da cidade de Barreiras-BA 2003. Recuperado de http://www.ebah.com.br/content/ ABAAAe0asAE/estudo-sobre-as-expectativas-grupo-recrutas-com-relacao-aotrabalho-desempenhado-no-exercito-cidade-barreiras-ba

PAIVA, A. D. A excelência gerencial na formação do oficial da academia militar das Agulhas Negras. In: IV Encontro Pedagógico do Ensino Superior Militar 2012. Suplemento da Revista de Villegagnon, Anais... Rio de Janeiro, RJ.

PAIVA, D.; FELICIANO, R. Estagiar na academia militar. Proelium: Revista da Academia Militar, v. 13, p. 305-309, 2010. 
PARADISO, Â.C.; SARRIERA, J.C. Experiências ocupacionais no desenvolvimento de carreira de jovens trabalhadores. Revista Brasileira de Orientação Profissional, v. 10, n. 2, p. 93-104, 2009.

PICARÓ, J.; SARMENTO, M.; SILVA, J. O papel dos recursos humanos na gestão da mudança. O caso do Regimento de Artilharia Antiaérea, n.1. Proelium, v. VII, n. 11, 271-295. 2016.

POLYDORO, S. A. J.; AZZI, R. G. O processo de ensinar em cursos de psicologia na perspectiva dos estudantes. Avaliação Psicológica, v. 10, n. 3, p. 365-386, 2011.

ROSSI, R. A. Vocação, tradição ou profissão um estudo sobre a escolha profissional e a evasão escolar na escola preparatória de cadetes do exército. (Mestrado em educação) - Curso de Pós-Graduação em Educação, Universidade Estadual de Campinas. Campinas. 2001. 173f.

SCHAFFEL, S. Ciências militares e formação profissional. In: J. C. GOMES; S. SCHAFFEL; D. DURAN. (Orgs). Ciências militares em foco. Rio de Janeiro: Centro de Estudos de Pessoal, 2010, p. 35-57.

SILVA, A. O. O sistema de avaliação do pessoal militar do exército. Revista das Ciências Militares, n. 14, p. 32-48, 2007.

SILVA, M. P. M. Ritos de passagem na formação do oficial combatente do exército brasileiro. Revista Pedagógica: Escola Preparatória dos Cadetes do Exército - EsPCEx, v.11, p. 2630, 2008.

SPARTA, M.; GOMES, W. B. Importância atribuída ao ingresso na educação superior por alunos do ensino médio. Revista Brasileira de Orientação Profissional, v. 6, n. 2, p. 45-53, 2005.

TRIGO, Y. F. Escola de Comando e Estado-Maior do Exército Tradição, mística e valores militares: a importância de sua manutenção na Academia Militar das Agulhas Negras para a formação do oficial brasileiro combatente de carreira do futuro, face aos desafios culturais do Século XXI - (Trabalho de Conclusão de Curso). 2013.125f.

VELHO, G. Projeto e metamorfose. Petrópolis: Jorge Zahar, 2003.

Osmar Prata Machado é psicólogo pela UERJ (Universidade Estadual do Rio de Janeiro).

E-mail: osmar64prata@gmail.com

Reivani Chisté Zanotelli Buscacio é doutora em Psicologia pela Pontifícia Universidade Católica do Rio de Janeiro (PUC/RJ). Professora na Universidade

Veiga de Almeida (UVA) E-mail: reivani@gmail.com

Marcia Cristina Monteiro é psicóloga, doutoranda em Psicologia Social pela Universidade Salgado de Oliveira (UNIVERSO), mestre em Psicologia Social 
pela Universidade Federal do Rio de Janeiro (UFRJ) e professora na União das Instituições de Ensino de São Paulo (UNIESP) - Faculdade Duque de Caxias.

Fátima de Almeida Maia é mestre em Psicologia pela Universidade Salgado de Oliveira (UNIVERSO), doutoranda em Psicologia Social pela mesma instituição.

Denise Amorim Rodrigues é mestre em Psicologia pela Universidade Gama Filho (UGF- RJ). Professora auxiliar da Universidade Estácio de Sá (UNESA-RJ).

Adriana Benevides Soares é pós doutora em Psicologia pela Universidade Federal de São Carlos (UFSCar). Professora titular da Universidade Salgado de Oliveira (UNIVERSO) e professora associada da Universidade do Estado do Rio de Janeiro

(UERJ).

E-mail: adribenevides@gmail.com 